\title{
Correction to: Understanding the Market Through Bicycle Statistics
}

\section{Correction to:}

Chapter 2 in: C. Mari, A Business History of the Bicycle Industry, https://doi.org/10.1007/978-3-030-50563-9_2

The original version of this chapter was inadvertently published without the source line for Table 2.1 in Chapter 2, which has now been corrected. The corrections to the chapter have been updated with the changes.

The updated version of this chapter can be found at https://doi.org/10.1007/978-3-030-50563-9_2

(C) The Author(s) 2021 